\title{
The Impact of Antidepressant Drug on the Physical and Psychological Status of the Hospitalized Burned Patient
}

\author{
Fathya R. Maghbool, Samia M. Abdel Dayem, Assem H. Kamel, Hemad M. Azab \& Zienab A. El-latif \\ Deputy Director Of Central Infection Control Unit In Assiut University Hospitals Egypt. \\ Professor of Psychiatric Nursing \& Mental Health, Faculty of Nursing, Alexandria University Egypt. \\ Professor of Plastic Surgery, Faculty of Medicine, Assiut University, Professor of Psychiatry, Faculty of Medicine. \\ Souhag University, Egypt. \\ Professor of Medical Surgical Nursing, Faculty of Nursing, Assiut University Egypt.
}

\begin{abstract}
Burn is a horrible accident that may occur to anyone. Burns result in severe psychological and emotional distress leading to severe depression. The study aim to determine impact of antidepressant drugs on the physical and psychological status of the hospitalized burned patient. Methods: The study was conducted in the burn unit at Assiut university hospital. Study design: The sample including sixty adult patients divided into study and control groups ,all nurses who were work with those patients in both groups in selected area. Beck Depression scale was applied to evaluate depression level of the patients in both groups, antidepressant drugs are given to study group for six weeks consecutively. Results: The majority of $66.7 \%$ their age less than 25 years old, $63.3 \%$ were females, 86.7\% flame burn, $93.3 \%$ accidental burn, $70.0 \%$ from both groups were suffering from severe depression on admission, the improvement of depression started within the first week conclusion: Antidepressant drugs improves depression levels, patient cooperation and nurse satisfaction in burn unit. Recommendations: This study highlights the importance management of depression in burn patients by antidepressant drug after the third day from admission. Nurses who work in burn unit need special attention to reduce Professional nursing burnout.
\end{abstract}

\section{Keywords: Antidepressant Drugs, Physical, Psychological Status \& Burned Patient}

\section{Introduction}

Burn has been defined as a necrotic and coagulates destruction of skin tissue due to transfer of energy from a heat source to the body by a thermal, electrical chemical, radioactive agent (Smeltzer \& Bare, 2008). Harold et al., (2003), added that burn has a significant alteration in the functioning and structural integrity of the skin which acts as a psychosocial mediator between a person and society to resume a social role. In addition, all body systems change such as vascular, pulmonary, renal system, and gastrointestinal system.

During acute phase of the burn management the patient needs too much efforts from medical treatment and nursing management (physical, psychological and social needs), these needs such as, continued assessment and maintenance of respiratory and circulatory status, fluid and electrolyte balance, gastrointestinal function, infection prevention and burn wound care i.e., wound cleaning, topical antibacterial therapy, wound dressing, dressing change, wound debridement and wound grafting . So, during the acute phase the shock of the accident has begun to lift and the patients begin to respond to their injuries as well as to the staff and the hospital routine (Smeltzer \& Bare, 2000).

As regard nurses, who care for patient with burned injuries, they need a high level of knowledge relating to the severity of the injury, the circumstances surrounding the injury and the patient mental \& emotional condition. So, that the nursing care can help the patients with negative emotional reactions to their burn and treatment to minimize the effect of these reactions. The nurse must also be able to communicate effectively with burn patients, and their families (Zhonghuq, 2002).

Burn complications resulting from complex problems, these problems affect all body systems and become life threatening. Most of the burned patients suffer from depression, anxiety and post traumatic stress disorders which are commonly occurred earlier and severer with hospitalized burned patients. Depression and anxiety related to visibility of burned injury, body image dissatisfaction, and social problems, also the patients worried about the possibility to resume their work, maintain their family relationship, and are able to join the society again (Smeltzer \& Bare, ( 2008)

The antidepressant for adult hospitalized burned patient is necessary to alleviate depression which often manifested by biological signs and symptoms like insomnia, agitation, loss of appetite \& constipation. The burn patients often are uncooperative \& neglected their physiotherapy. Antidepressant drugs may have an effect on the burn 
patient's cooperativeness, subjective feelings \& lead to reduction of the biological signs and symptoms of depression which intern will improve the health and quality of life of the patient with burn injury (Smeltzer, 2004 \& El Hamaui, 2002).

\section{Aim of the Study}

The present study aims to determine the impact of antidepressant drug on the physical and psychological status of the hospitalized burned patient.

\section{Research Hypothesis}

- Antidepressant drug will improve the physical status and depression level of hospitalized burned patients.

- The use of antidepressant drug improves the nurse satisfaction and patient cooperation.

\section{Materials \& Method}

\section{Study design}

Quasi experimental design was utilized to determine the impact of antidepressant drug on the physical and psychological status of the hospitalized burned patient.

\section{Setting}

The study was conducted in the burn unit, which consisted of four parts: Emergency Room, Intensive Care Unit, male and female wards at Assiut University Hospital, Egypt.

\section{Validity and reliability}

Content and face validity was ascertained through experts. Those experts included five experts in Medical Surgical Nursing and two experts in surgical and psychiatric department at Faculty of Medicine , Assuit university hospital .The selected tools were translated into Arabic by the researcher and back to English by the five experts. The needed modifications of some Arabic words were done. Their opinions were elicited regarding to the tools format layout, consistency and scoring system. Contentes of the tools were measured regarding, accuracy of knowledge, relevance and competence. Testing reliability of the tools items was done using Cronbach alpha test, tool I=0.91, tool II,0.84, tool III 0.93 and Tool IV, 0.92. Also the content validity of the educational materials was tested by the same experts.

\section{Subjects}

The subjects of this study were consisted of two groups:

I. Group one: The study subjects were entailing a convenient sample of 60 recent hospitalized burned patients. They divided equally into study and control groups 30 patients each from adult patients, their ages ranging from 18 to 45 years old, males and females, extent burn from $15-45 \%$ and the degrees of burn were mixed between $1^{\text {st }}, 2^{\text {nd }}$ and $3^{\text {rd }}$ degree. Both groups should be free from chronic diseases requiring specific therapy as anemia, peptic ulcer or gastro intestinal tract disturbance, cardiac or thyroid disease, diabetes mellitus and pregnancy.

II. Group two: Consisted of seventeen nurses who were assigned to provide direct care for burned patients in the burn unit at Assiut University Hospital.

Tools: Four tools were utilized to data collection.

Tool- I- Patient Physical Assessment Structured Interview Schedule

This tool was constructed by the researcher based on the current national and international review of literatures in order to assess the patients' physical status of burn injury and it was consisted of two parts:

\section{Part (1): Patients sociodemographic data}

This part included socio- demographic data of burned patients such as: age, gender, educational level, marital status, family size, occupation. In addition, it was included admission and discharge date.

Part (2): Physical Assessment of burn injury.

It was included the assessment of physical condition and burn injury such as: Type, cause, percentage, site, depth, place of burn injury, using role of nine, burn seem to be suicidal, homicidal or accidental.

\section{Tool II- Beck Depression Scale}

This scale was developed by Beck (1965). It was translated into Arabic Language by the researcher, it was consisted of 21 main items used to evaluate the level of patients depression e.g. sadness, hopelessness ,dissatisfaction, failure, guilty, punishing, disappointing, anhedonia, killing himself, crying irritating, social isolation, decisions making ,body image, low effort and sleeping.. The validity and reliability for the Arabic version were done, and score for depression level was as the following:

\begin{tabular}{|l|c|}
\hline \multicolumn{2}{|l|}{ Score for depression } \\
\hline \multicolumn{1}{|c|}{ Levels of depression } & Total score \\
\hline $\begin{array}{l}\text { These ups and downs } \\
\text { are considered normal }\end{array}$ & $0-10$ \\
\hline Mild mood disturbance & $11-16$ \\
\hline $\begin{array}{l}\text { Borderline clinical } \\
\text { depression }\end{array}$ & $17-20$ \\
\hline Moderate depression & $21-30$ \\
\hline Severe depression & $31-40$ \\
\hline Extreme depression & over 40 \\
\hline
\end{tabular}


Tool - III- Antidepressant Drug Monitoring Sheet It was developed by the researchers to monitor the side effect of antidepressant drug provided for the patients. It included name, dose, route, time, and the possible side effect of the drug (nausea, vomiting, insomnia, diarrhea, etc).

Data was collected and analyzed by computer program (Statistical Package for Social Sciences (SPSS), version 17).

Data was expressed as mean \pm standard deviation (SD), number, and percentage. Chi-square test was used to compare data, while $t$-test was utilized for the comparison between groups. Pearson correlation was done to determine significance between variable in each group.

Tool - IV - Assessment of Patient's Cooperation with the Nurses Structured Interview Schedule

This tool was developed in an Arabic language by the researcher to assess the cooperation between patient and nurse, during providing nursing interventions fulfilled by the nurse who assigned for nursing management of the patient in both groups per day for six weeks. This tool included, transferring the patient from the bed to dressing room ,removing the old dressing, shower bath before dressing ,cleaning the wound from the dead tissues and wound management during the evening and night, pre and post-operative care, during the dressing on the patient . Physiotherapy care (hydrotherapy, daily passive and active exercise, change splint and change positions) nutritional management (advising the patient for important of nutrition support, daily meals and giving medication.

\section{Procedure}

- An official permission was taken from the director of the hospital and head of the burn unit after explaining the nature, design, and the objective of the study and ethical approval for the study was obtained from Faculty of Medicine Research Ethics Committee (REC), Assiut University, Assiut, Egypt.

- Patient verbal and written consent were also obtained from both study and control groups. They were assured about confidentiality and maintenance of their privacy.

- The control group (30 patients) was the first 30 patients meeting the inclusion criteria, they did not receive the antidepressant drug, but they receive the hospital routine of medical and nursing managements. Pilot study was done to assess applicability and modification for study tools. Using the study tools, I, II and IV, with this group except the antidepressant monitoring tool (it was used with the study group). While the study group was the second 30 patients meeting the inclusion criteria, the researcher administered the study tools I, II, III and IV with this group. They received the antidepressant drug after third day and continuing to 6 weeks consecutively and also they received the hospital routine for medical and nursing managements.

- Each patient of both groups was interviewed by the researcher at $1^{\text {st }}$ day of admission by using tool I regarding to demographic data to evaluate the patient condition of burn circumstances, burn wound and to evaluate that the patient free from physical illness or medical condition requiring specific therapy or not.

- The researcher was fulfilled the data from all the nurses who assigned for nursing management of the patient in both groups, every day for six weeks to evaluate the cooperation of the patient with the nurse and nurse satisfaction with the patient in burn unit using tool IV.

- On the third day of the onset of burn occurrence patient who were participating in group II (study group) started the antidepressant drug and continuing to six weeks consecutively after taking the patient consent, explain the effect of the drug, maintain the patient privacy and confidentiality. The antidepressant drug used was Cipralex tablets; it was used for the treatment of depression. Cipralex was a Selective Serotonin Reuptake Inhibitor (SSRI). This medicine helps to formalize the levels of serotonin in the brain. Disturbances in the serotonin of the brain are key factors in the development of depression and related disorders especially the patient ability to cope with daily tasks. The drug dose was $(10 \mathrm{mg})$ taken every day as a single daily dose before sleeping. Cipralex was taken with or without food.

- Antidepressant monitoring tool was fulfilled by the researcher to monitor the side effect of antidepressant drug provided for the patients. With no side effect was found.

- Beck depression scale was fulfilled by the researcher from patients of both groups, two times weekly for six weeks or up to the patient discharge using tool II.

\section{Limitation of The Study}

The number of the patient was limited because the specific criteria of the sample and low flow of the patients in burn unit, the study conducted within one year for the study and control groups. 


\section{Results}

Table (1): Socio-demographic characteristics of patients in the study and control groups, $(\mathrm{N}=60)$.

\begin{tabular}{|c|c|c|c|c|c|c|}
\hline \multirow{3}{*}{ Item } & \multicolumn{4}{|c|}{ Group } & \multirow{3}{*}{ T-test } & \multirow{3}{*}{ p-value } \\
\hline & \multicolumn{2}{|c|}{ Study $(n=30)$} & \multicolumn{2}{|c|}{ Control $(n=30)$} & & \\
\hline & No. & $\%$ & No. & $\%$ & & \\
\hline \multirow{3}{*}{$\begin{array}{l}\text { Age (years) } \\
<25 \\
25+\end{array}$} & & & & & & \\
\hline & 20 & 66.7 & 16 & 53.3 & & \\
\hline & 10 & 33.3 & 14 & 46.7 & 1.11 & 0.29 \\
\hline \multicolumn{7}{|l|}{ Sex } \\
\hline \multirow{2}{*}{$\begin{array}{l}\text { Male } \\
\text { Female }\end{array}$} & 11 & 36.7 & 10 & 33.3 & & \\
\hline & 19 & 63.3 & 20 & 66.7 & 0.07 & 0.79 \\
\hline \multirow{5}{*}{$\begin{array}{l}\text { Education } \\
\text { Illiterate } \\
\text { Read/write } \\
\text { Basic/secondary } \\
\text { University }\end{array}$} & & & & & & \\
\hline & 7 & 23.3 & 7 & 23.3 & & \\
\hline & 18 & 60.0 & 10 & 33.3 & 12.45 & 0.21 \\
\hline & 5 & 16.7 & 11 & 36.7 & & \\
\hline & 0 & 0.0 & 2 & 6.7 & & \\
\hline \multirow{3}{*}{$\begin{array}{l}\text { Marital status } \\
\text { Married } \\
\text { Unmarried }\end{array}$} & & & & & & \\
\hline & 17 & 56.7 & 16 & 53.3 & & \\
\hline & 13 & 43.3 & 14 & 46.7 & 0.07 & 0.80 \\
\hline \multirow{4}{*}{$\begin{array}{l}\text { Job } \\
\text { Manual worker } \\
\text { Employee } \\
\text { Unemployed }\end{array}$} & & & & & & \\
\hline & 11 & 36.7 & 13 & 43.3 & & \\
\hline & 7 & 23.3 & 7 & 23.3 & 0.35 & 0.84 \\
\hline & 12 & 40.0 & 10 & 33.3 & & \\
\hline \multicolumn{7}{|l|}{ Family size } \\
\hline \multirow{4}{*}{$\begin{array}{l}<4 \\
4+ \\
\text { Range } \\
\text { mean } \pm \text { SD }\end{array}$} & 15 & 50.0 & 11 & 36.7 & & \\
\hline & 15 & 50.0 & 19 & 63.3 & & \\
\hline & \multicolumn{2}{|c|}{$0-10$} & \multicolumn{2}{|c|}{$2-11$} & & \\
\hline & \multicolumn{2}{|c|}{$3.8 \pm 2.0$} & \multicolumn{2}{|c|}{$4.6 \pm 2.1$} & 1.39 & 0.24 \\
\hline \multicolumn{7}{|l|}{ Concomitant disease } \\
\hline \multirow{2}{*}{$\begin{array}{l}\text { No } \\
\text { Yes }\end{array}$} & 30 & 100.0 & 29 & 96.7 & & \\
\hline & 0 & 0.0 & 1 & 3.3 & 1.45 & 1.00 \\
\hline
\end{tabular}

Table (2): Comparison of depression mean scores among patients in the study and control group, $(\mathrm{N}=60)$.

\begin{tabular}{|l|c|c|c|c|}
\hline \multicolumn{1}{|c|}{ Depression } & Study group & Control group & \multirow{2}{*}{ T-test } & P-value \\
\cline { 2 - 5 } & mean \pm SD & mean \pm SD & & P $=0.483 \mathrm{n} . \mathrm{s}$ \\
\hline On admission & $55.0 \pm 10.34$ & $48.1 \pm 12.28$ & 12.45 & $\mathrm{P}=0.548 \mathrm{n} . \mathrm{s}$ \\
\hline First follow up & $47.0 \pm 9.85$ & $47.0 \pm 10.24$ & 14.27 & $\mathrm{P}<0.02^{*}$ \\
\hline Second follow up & $29.0 \pm 6.87$ & $46.0 \pm 14.25$ & 8.23 & $\mathrm{P}<0.001^{* *}$ \\
\hline Third follow up & $18.2 \pm 5.98$ & $44.5 \pm 15.23$ & 22.3 & $\mathrm{P}<0.001^{* *}$ \\
\hline Fourth follow up & $13.0 \pm 3.23$ & $43.0 \pm 12.23$ & 18.24 & $\mathrm{P}<0.000^{* * *}$ \\
\hline Fifth follow up & $10.4 \pm 2.89$ & $42.5 \pm 15.26$ & 16.42 & $\mathrm{P}<0.000^{* * *}$ \\
\hline Six follow up & $9.5 \pm 2.54$ & $41.1 \pm 13.25$ & 17.23 & $\mathrm{P}<0.000^{* * *}$ \\
\hline Seven follow up & $8.0 \pm 2.56$ & $43.2 \pm 17.31$ & 25.20 & $\mathrm{P}<0.000^{* * *}$ \\
\hline Eight follow up & $7.5 \pm 1.58$ & $44.0 \pm 16.45$ & 26.30 & $\mathrm{P}<0.000^{* * *}$ \\
\hline Nine follow up & $8.0 \pm 2.14$ & $46.0 \pm 17.53$ & 27.80 & $\mathrm{P}<0.000^{* * *}$ \\
\hline Ten follow up & $9.5 \pm 3.57$ & $48.0 \pm 16.43$ & 22.30 & $\mathrm{P}<0.000^{* * *}$ \\
\hline Eleven follow up & $10.2 \pm 2.14$ & $46.0 \pm 17.36$ & 25.15 & \\
\hline
\end{tabular}


Table (3): Mean scores of patients cooperation and nurses' satisfaction of the study and control group, $(\mathrm{N}=60)$.

\begin{tabular}{|c|c|c|c|c|c|c|}
\hline \multirow{3}{*}{ Item } & \multicolumn{2}{|c|}{ Patients cooperation } & \multicolumn{2}{|c|}{ Nurse satisfaction } & \multirow{3}{*}{$\begin{array}{l}\text { p-value } \\
\text { patients }\end{array}$} & \multirow{3}{*}{$\begin{array}{l}\text { p-value } \\
\text { nurses }\end{array}$} \\
\hline & Study & Control & Study & Control & & \\
\hline & mean \pm SD & mean \pm SD & mean \pm SD & mean \pm SD & & \\
\hline Wks.1 & $47.0 \pm 10.25$ & $36.0 \pm 10.27$ & $45.0 \pm 8.43$ & $43.0 \pm 9.71$ & n.s & n.s \\
\hline Wks.2 & $76.0 \pm 15.41$ & $40.1 \pm 8.59$ & $83.0 \pm 7.54$ & $45.11 \pm 8.36$ & $\mathrm{P}<0.001 * *$ & $\mathrm{P}<0.001 * *$ \\
\hline Wks.3 & $82.0 \pm 11.24$ & $42.0 \pm 9.75$ & $90.0 \pm 10.23$ & $46.4 \pm 7.42$ & $\mathrm{P}<0.000 * * *$ & $\mathrm{P}<0.000 * * *$ \\
\hline Wks.4 & $87.0 \pm 17.30$ & $50.0 \pm 9.88$ & $94.0 \pm 14.37$ & $45.0 \pm 9.71$ & $\mathrm{P}<0.001 * *$ & $\mathrm{P}<0.000 * * *$ \\
\hline Wks.5 & $83.0 \pm 13.20$ & $55.5 \pm 8.73$ & $85.0 \pm 15.72$ & $46.0 \pm 8.56$ & $\mathrm{P}<0.001 * *$ & $\mathrm{P}<0.000 * * *$ \\
\hline Wks.6 & $85 \pm 13.42$ & $56.0 \pm 9.11$ & $84.1 \pm 12.87$ & $47.0 \pm 10.32$ & $\mathrm{P}<0.001 * *$ & $\mathrm{P}<0.000 * * *$ \\
\hline
\end{tabular}

Table (4): Correlation among Scores of patient cooperation, nurses' satisfaction, and level of depression in the study and control groups, $(\mathrm{N}=60)$.

\begin{tabular}{|c|c|c|c|c|}
\hline \multirow[b]{3}{*}{ Item } & \multicolumn{4}{|c|}{ Pearson correlation coefficient } \\
\hline & \multicolumn{2}{|c|}{ Study group $(n=30)$} & \multicolumn{2}{|c|}{ Control group $(n=30)$} \\
\hline & $\begin{array}{c}\text { Patient } \\
\text { cooperation }\end{array}$ & $\begin{array}{c}\text { Nurse } \\
\text { satisfaction }\end{array}$ & $\begin{array}{c}\text { Patient } \\
\text { cooperation }\end{array}$ & $\begin{array}{c}\text { Nurse } \\
\text { Satisfaction }\end{array}$ \\
\hline Nurse satisfaction & $0.95 *$ & -- & $0.96 *$ & --- \\
\hline Level of depression & $-0.99 *$ & $-.92 *$ & 0.37 & 0.16 \\
\hline
\end{tabular}

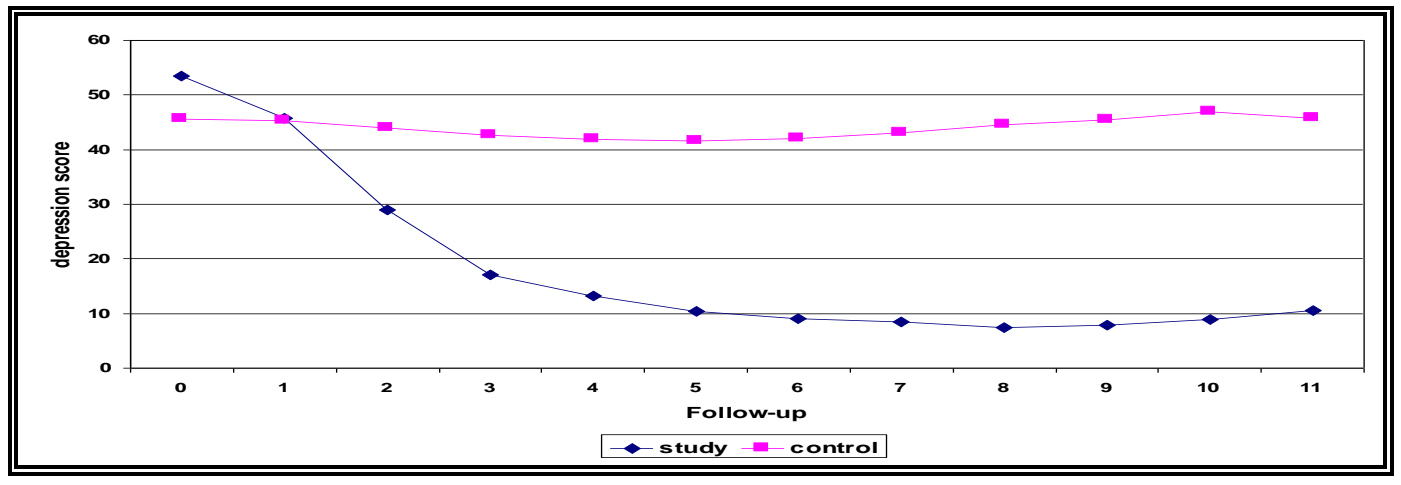

Fig (1): Comparison of mean scores of depression among patients in the study and control group, $(\mathrm{N}=60)$.

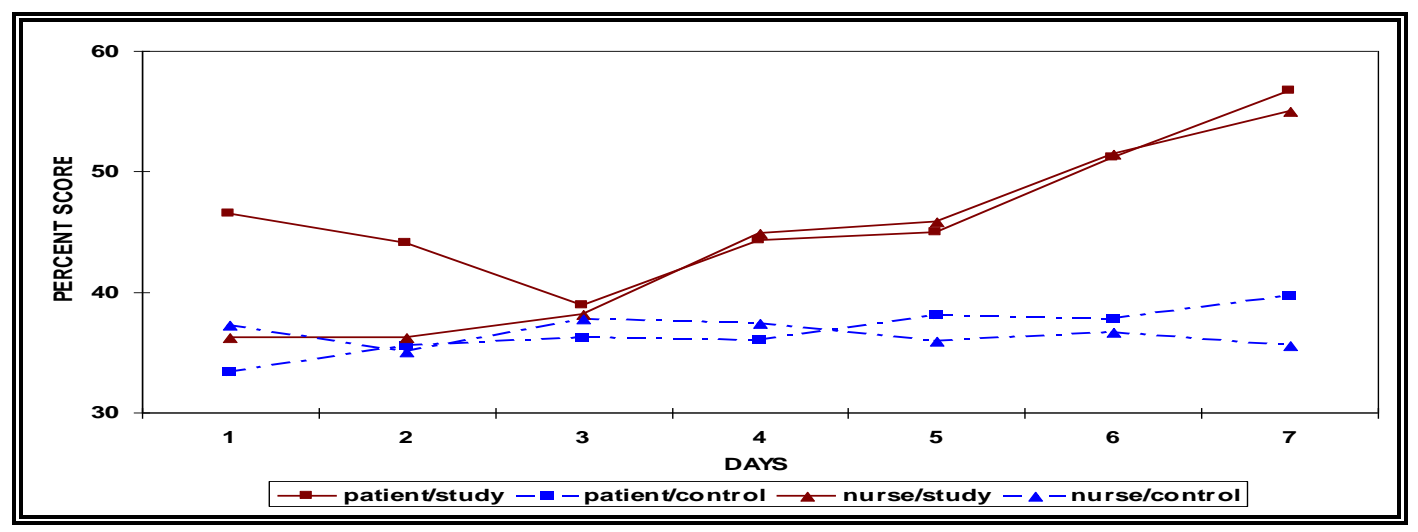

Figure (2): Comparison of mean scores of patient's cooperation and nurses' satisfaction of the study and control groups in the first week, $(N=60)$ 


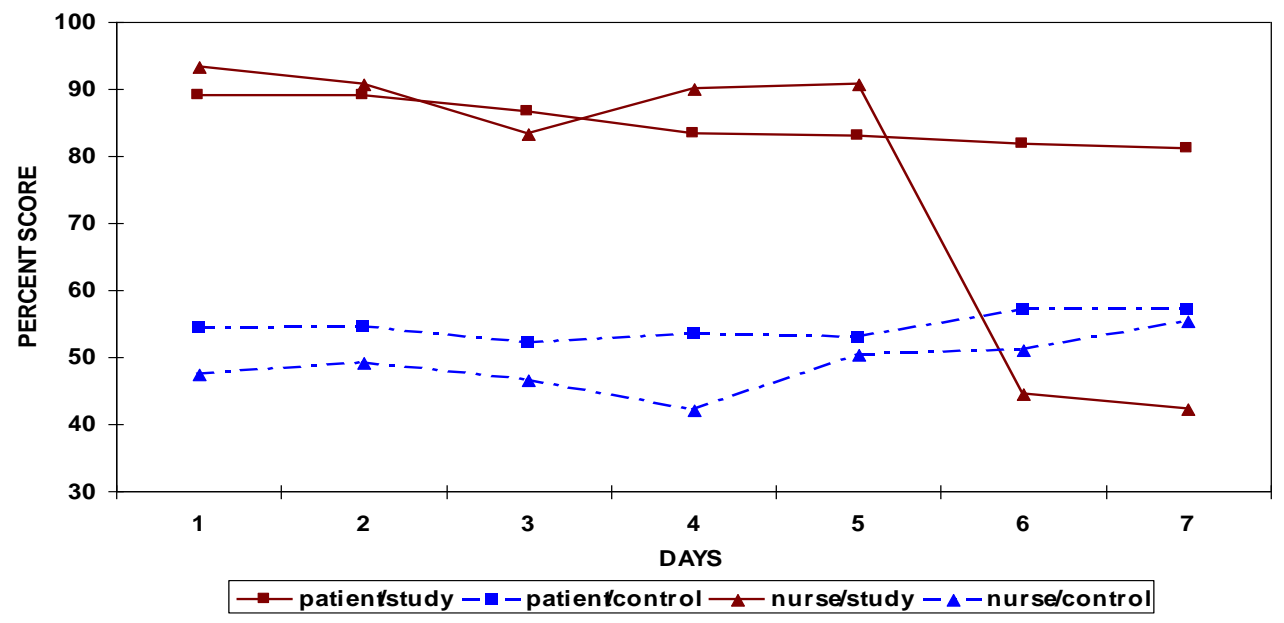

Figure (3): Comparison of the patient's cooperation and nurses' satisfaction of the study and control group at the fifth week. , $(\mathrm{N}=60)$.

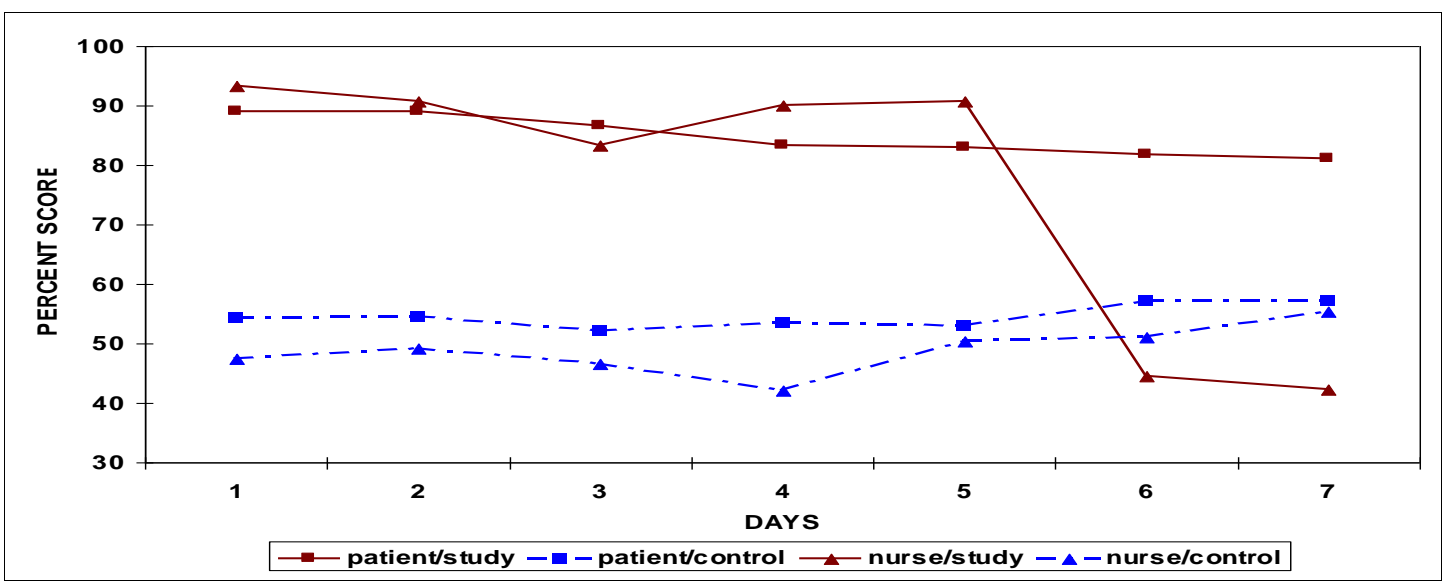

Figure (4): Comparison of the patient's cooperation and nurses' satisfaction of the study and control group at the sixth week. , $(\mathrm{N}=60)$.

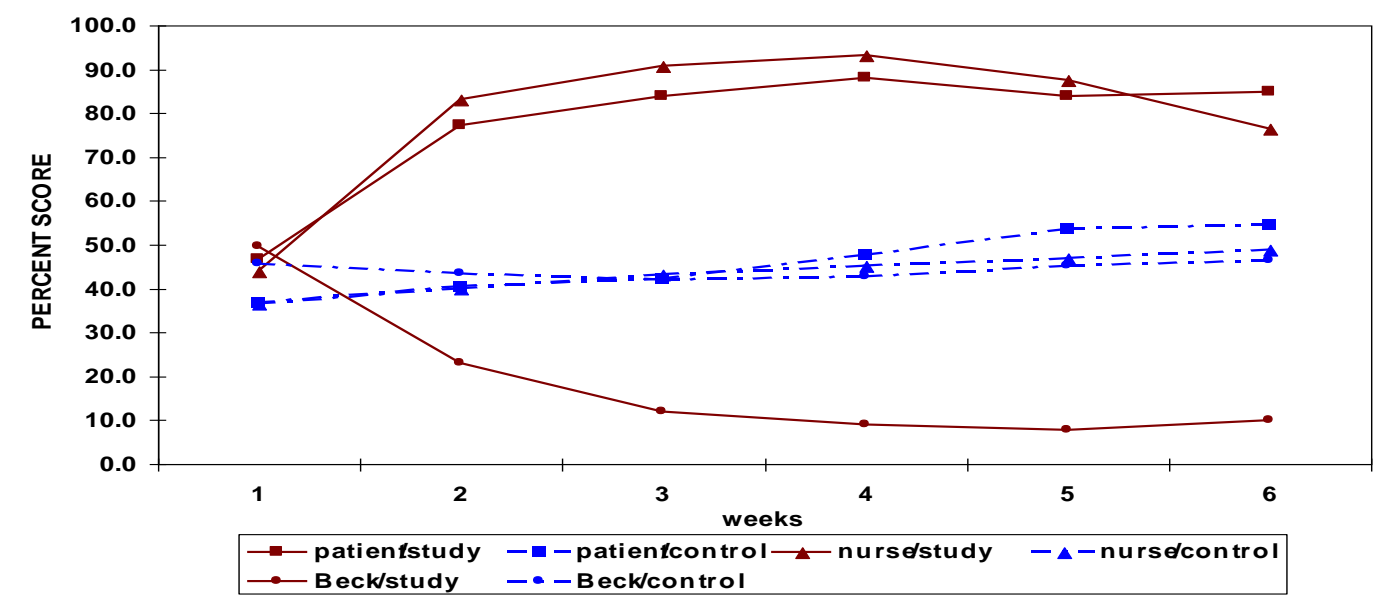

Figure (5): Relations among scores of patient cooperation, nurses' satisfaction, and level of depression in the study and control groups, $(\mathrm{N}=60)$. 
Table (1): Shows the majority of the study group $66.7 \%$ their age less than 25 years old, $63.3 \%$ were females , $60.0 \%$ have read and write $56.7 \%$ were married, $40.0 \%$ unemployed, mean $\pm \mathrm{SD}$ of family size 3.8 \pm 2.0 . There were no significant differences in both groups as regarding to socio-demographic characteristics among the patient in the study and control group. This means that the two groups are matched.

Table (2): Shows the depression mean scors in both study and control group there were no significance difference on admission and first follow up mean \pm SD was, $55.0 \pm 10.34,48.1 \pm 12.28$ respectively. While from the second follow-up there were mild significant difference was shown in both groups. From third to eleventh follow up there were highly significance differences were shown in both groups, the mean \pm SD was $10.2 \pm 2.14 \& 46.0 \pm 17.36$ and $(\mathrm{P}<0.00)$ respectively.

Table (3): Shows the mean scores of patient cooperation and nurse's satisfaction, in the both groups throughout the study. There was no significance difference between study and control in patients and nurses in the first week at $(\mathrm{P}>0.05)$. Regarding patients cooperation there were significance differences between study and control, mean \pm SD $(85 \pm 13.42)$ and $56.0 \pm 9.11$. Also there were a highly significance differences between study and control group in nurse's satisfaction, mean $\pm \mathrm{SD}$ $84.1 \pm 12.87$ and 47.0.0 $\pm 10.32,(\mathrm{P}<0.000)$.

Table (4): There was a positive correlation between patient's cooperation and nurse satisfaction $(\mathrm{P}<0.05)$ and there was a negative correlation in the study group between patient's cooperation and the levels of depression $(\mathrm{P}<0.05)$.

Figure (1\&2): As regarding the patient cooperation in the study group in the first week, the patients were cooperative more than patients in the control group. Nurses were satisfied in the study group at the first week than the nurse in the control group.

Figure (3): The patients in the study group were still cooperative near the discharge (fifth week), while the nurses having dissatisfaction from fifth to seventh day. But the patients in the control group were still uncooperative and the nurses were still dissatisfied.

Figure (4): The patients in the study group were still cooperative near the discharge (sixth week) but the nurses still having dissatisfaction. While the patient in the control group still uncooperative and the nurses were still dissatisfied.

Figure (5): As regarding the relations among scores of patient cooperation, nurse satisfaction, and levels of depression in the study and control groups throughout the study.

\section{Discussion}

Burn injury may affect all aspects of human life, leaving survivors with a variety of physical and psychosocial handicaps. In addition, altered appearance and stigmatization may represent a threat to patient social life. Also physical and psychological aspects of burn injury have been researched in different parts of world producing different outcomes; Somatic symptoms are generally persistent and psychiatric disorders such as post-traumatic stress disorders and depression are relatively frequent (Esselman 2007).

The most commonly affected group regarding the gender in the study and control group were the females. This result was in agreement with Brienza et al., (1987) who report a pilot research project carried out in four Burn Centers in Southern Italy showed that the sex was the most prominent adult's females. Ishtiaq \& Umar (2008), they studied a retrospective observational study conducted on burn patients $(82.02 \%)$ were females accidental burns, Table (1).

The most common psychiatric disorders are depression, with hospitalized burned patient especially who has major burn injuries, also burn injuries are devastating, sudden and unpredictable forms of trauma which affect the victim both physically and psychologically. Dalal, (2010). In the present study by using Beck depression scale it was found the most of the patients were suffering from severe depression on the first week of admission (Table 2) \& Fig (1): Also this was similar to Wiechman et al., (2001) who studied hospitalized burned patient to determine the rates and severity of depression over one month the Beck Depression Inventory was administered at 1 month, $54 \%$ of patients showed symptoms of moderate to severe depression. Dyster, (2008), who studied burned patients found that $(66 \%)$ of their patients committed severe depression from the total cases.

As regards to the effect of the burns on the patient cooperation with the nurse in burn unit, in the present study the follow-up of the patients were for 42 day continuously, the study showed that most of the patients were uncooperative in both groups on the admission, this uncooperative continue with the control group until nearly discharge. This means that burned patients were not cooperative with the staff when they were giving them nursing care,(Table 3)\& Fig (2): This result was in agreement with, Smeltzer \& Bare (2008), who stated that the burn patient was facing the reality of the burn trauma and was grieving over obvious losses, depression, regression, and manipulative behavior are common responses of patients who have burn injuries. Withdrawal from 
participation in required treatments and regression must be viewed with an understanding that such behavior helps the patient cope with an enormously stressful event. Rea et al., ( 2006), clarify much of the patient's energy goes into maintaining vital physical functions and wound healing in the early post burn weeks, leaving little emotional energy for cooperation or coping in more effective manner.

The present study showed that the most of the nurses who worked in burn unit have low satisfaction with the patient specially the nurses who work with the control group and at the first week of the study, (Table 3) \& (Fig (2): This result supported by Matthew et al., (2011) they stated that working in a burn unit has been described as a stressful occupation. Every nurse who cares for a burn patient knows that stress was a part of working in this field, some authors have emphasized that these nurses experience dealing with self-inflicted burns, uncooperative patients, inter-staff conflicts and dying patients on a daily basis. These factors in burn unit have put nurses under a huge pressure and many times they have indicated that they haven't any motivations to work. Also unresolved job stress may results in emotional withdrawal and burnout leading to reduce the nurses' activity and their contact with patients. Steenkamp et al., (1998), clarified the professional nursing burnout has been defined as a syndrome manifested by emotional exhaustion, depersonalization, and reduced personal accomplishment.

Table (4) \& (Fig 4): demonstrated that burnout was significantly correlated with reduced nurse satisfaction with work. Nurses were works in burn unit are deemed to be at a higher risk of experiencing burnout than other professions area because of the implicit relationship of job stress to burnout. Moreover nurses in burn unit are responsible for the patient to develop effective coping strategies by setting specific expectations for behavior, promoting truthful communication to build trust, helping patients practice appropriate strategies, and giving positive reinforcement when appropriate. Most importantly, the nurse and all members of the health care team must demonstrate acceptance of the patient and this means that nurse should accept the patient as he was Smeltzer \& Bare (2008).

The present study showed that the nurses' satisfaction in work with the study group, improved due to the improvement of the patient cooperation after he had taken the antidepressant drug and the cooperation of the patient was considered an important factor from many factors which can improve the nurse satisfaction in burn unit, this is assured through making a correlation among scores of patient cooperation and nurse satisfaction, in the study and control group. This supported by Rafiei et al., (2007). They mentioned nursing care in a burn unit was demanding intensive care which provokes emotional responses among staff. Some of these responses focused on the kind of care, patient cooperation and some involved feelings and emotions of the participant's patient. Issues related to the patients in burn unit may leads to intense reactions in the staff which finally results in dissatisfaction of the nurse and exerts negative influences on nursing care. Matthew et al., (2011) add job dissatisfaction among nurses contributes to risk of the patients and the patient cooperation was lower with the nurses who are dissatisfied. Also they that found improving nurses' working conditions may improve both nurse's satisfaction and emotion of the patients' as well as the quality of care.

As the result of the effect of the antidepressant drug on patients in the present study, patient were highly cooperative with the nurses; this cooperation was reflected on the nurse, leading to the nurse to be more satisfied with patients. but while the patient still cooperative near the discharge (fifth week), the nurses having dissatisfaction so, sometime the nurses in burn unit was suffering from burnout even if the patient was cooperative with her and even if the patient was taking the antidepressant drugs Figure (4\&5) .This result was supported by Fauerbach, (2007) who stated working in a burn unit has been described as a stressful occupation and the unresolved job stress may results in emotional withdrawal and burnout. On the same line Aleandri et al., (2006) emphasis that Professional nursing burnout was a condition where a nurse experiences chronic fatigue, exhaustion, tiredness, anger, irritability, difficulties on account of work and the stress may be affecting professional performance. Every nurse who cares for a burn patient knows that stress was a part of working in this field, Patten, (2001).

On the other hand, there were changes in the level of depression from normal to mild depression on the last day from the sixth week at the discharge from the burn unit. This supported by Zhonghua, (2002) who stated, when the burn patients are ready to discharge from the hospital he was suffering from depression due to visibility of body image dissatisfaction, leading to social problems because the patients worn about the possibility to resume their work, maintain their family relationship, and be able to join the society again. Rea et al., (2006) suggested that women have more psychological problems in adjusting to burn injuries, where the ensuring disfigurement was visible. 


\section{Conclusions}

Based on the results of the present study, it can be concluded that the Antidepressant drug improved the physical and depression levels of hospitalized burned patients. Also the use of antidepressant drug improved the patient's cooperation and nurse satisfaction in burn unit. The nurse who works in burn unit suffering from burnout even the patient was cooperative with her because the working in a burn unit has been described as a stressful occupation.

\section{Recommendations}

By the end of the present study

- This study highlights the importance of the management of depression in burn patients by antidepressant drug after the third day from admission.

- The nurse who works in burn unit needs special attention from nursing administration in the hospital to reduce Professional nursing burnout by change the nurses from burn unite to another area every 2 year at least and give them motivations and some encouragement .

- Special psychiatric rehabilitation program must be start immediately after burn injury.

- Presence of psychiatrists and psychiatric liaison nurse among the burn team at any burn unit was extremely necessary.

\section{References}

1. Aleandri A., Sansoni J., (2006): Nurses and burnout: A survey in an emergency department in the Lazio Region. Prof Inferm. 59(3): 165-70.

2. Ambade N., Godbole V., Kukde G., (2007): Suicidal and homicidal deaths: comparative and circumstantial approach. J Forensic Leg Med; 14(5):253-60.

3. Essex L.( 1999): Burn tragedy Rehabilitation Nursing24(1).5-6.

4. Brienza E., Di Lonardo K., Minervini C., Portincasa K., (1987): The prevention of accidental burn at home: Annals of the M.B.C. vol. 1.

5. Dalal \& Rahul (2010): Psychiatric aspects of burn, Indian Journal of Plastic Surgery: 43, .136-42.

6. Dyster-Aas, J., Willebrand, M., Wikehult, B., Gerdin, B., \& Ekselius, L, (2008): Major depression and post-traumatic stress disorder symptoms following severe burn injury in relation to lifetime psychiatric morbidity. Journal of Trauma 64, 1349-1356.
7. Esselman C., (2007): Burn rehabilitation an overview. Archives of Physical Medicine and Rehabilitation. 88. S3-S6.

8. Fauerbach A., (1997): Preburn psychiatric history affects post-trauma morbidity. Psychosomatics; 38 (37) 4-85.

9. Harold l., \& Benjaming, (2003): Management of Depression, Comprehensive Textbook of Psychiatric. fifth edition. PP-154-158.

10. Ishtiaq A., (2008): Medicolegal aspects of burn victims. Pakistan Journal of Medical Science volume, 25, October-December.

11. Jordon S., \& Harrington T;(1997): Management of the burn Nursing wound, Clinics of North America., 32(2), 251-73.

12. Kathy Canon Wiechman (2001): Rates, Trends, and Severity of Depression after Burn Injuries. Journal of Burn Care \& Rehabilitation: 22 ( 6 ). Pp: 417-424.

13. Matthew D., HcHugh, Annkutney-Lee, Jeannie P., \& et al., (2011) dissatisfaction ,burnout and frustration with health benefits signal problems for patient care.Health Affairs 30, No 2.: 202-210.

14. Oster Cand Willembrand M., Dyster-Aas J., Kildal M., Ekselius L., (2009): Validation of EuroQoL questionnaire in burn injured adults. Burns , 35(5):723-732.

15. Patten, S., (2001): Improve of your social skills .Nurs . 23 (11): 84.

16. Rafiei Foroug, Haghdoust. Oskouei F., Yadaver. Nikravesh M., (2007): Response of nursing staff to burnout in burn centers of Tehran. IRAN JOURNAL OF NURSING (IJN); 19(48):7-24.

17. Rea M., Walters G., \& Wood M., ( 2006) :Surgeons and scars; differences between patient and surgeons in perceived requirement for reconstructive surgery following burn injury 32 ; $276-283$.

18. Sanchez L., Pereperez B., Bastida L., Martinez M., (2007): Cost-utility analysis applied to the treatment of burn patients in a specialized center. Arch Surge: 142(1): 50-7.

19. Smeltzer C., \& Breda G., (2008) Text book of Medical Surgical Nursing: Management of patients with burn injury. Brunner \& Suddarth's $\left(11^{\text {nth }}\right.$ ed) Lippincott Williams \&Wilkins : pp (1994-2039).

20. Smeltzer C., \& Bare, G., (2000): Management of burn injury.Bruner and suddar th's Text book of Medical - surgical Nursing. Lippincott Williams Wilkins. $9^{\text {th }}$ ed. 1501-1535.

21. Smeltzer C., \& Bare, G., (2004). Brunner \& suddarth's textbook of Medical surgical Nursing Lippincott Williams \&Wilkins : $10^{\text {th }} \mathrm{ed}, 1707$. 
22. El hamaoui Y., Yaalaoui S., Chihabeddine K., Boukind E., Moussaoui D., (2002): Posttraumatic stress disorder in burn patient's. Burns, 28(7) 647-50.

23. Steenkamp C., van der Merwe E., (1998): The psychosocial functioning of nurses in a burn unit. Burns, 24(3):235- 58.

24. Zhonghua xueyexue zazhi (2002) : Correlative analysis of the psychological Disorders With ability to resume work in Burn patient. Journal of Burn Care \& Rehabilitation: 18(5): 3

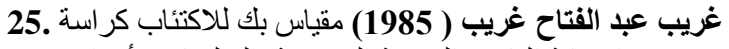

25. 